\title{
Climate change in arid lands and Native American socioeconomic vulnerability: The case of the Pyramid Lake Paiute Tribe
}

\author{
Mahesh R. Gautam • Karletta Chief • William J. Smith Jr.
}

Received: 27 November 2012 / Accepted: 4 March 2013 / Published online: 9 April 2013

(C) The Author(s) 2013. This article is published with open access at Springerlink.com

\begin{abstract}
The case of the Pyramid Lake Paiute Tribe exemplifies tribal vulnerabilities as a result of climate change. Preliminary socio-economic data and analysis reveal that the tribe's vulnerability to climate change is related to cultural and economic dependence on Pyramid Lake, while external socio-economic vulnerability factors influence adaptive capacity and amplify potential impacts. Reduced water supplies as a consequence of climate change would result in a compounded reduction of inflows to Pyramid Lake, thus potentially impacting the spawning and sustenance of a cultural livelihood, the endangered cui-ui fish (Chasmistes cujus). Meanwhile, limited economic opportunities and dwindling federal support constrain tribal adaptive capacity. Factors that contribute to tribal adaptive capacity include: sustainability-based values, technical capacity for natural resource management, proactive initiatives for the control of invasive-species, strong external scientific networks, and remarkable tribal awareness of climate change.
\end{abstract}

\section{Introduction}

Studies in the last two decades provide ample evidence of hydroclimatic changes in the Western U.S. linked to short and long term climate variability (Cayan et al. 2001; Coats 2010). In addition, Global Climate Model projections show temperature will significantly increase over the next 100 years and could disproportionately impact semi-arid regions of

This article is part of a Special Issue on "Climate Change and Indigenous Peoples in the United States: Impacts, Experiences, and Actions" edited by Julie Koppel Maldonado, Rajul E. Pandya, and Benedict J. Colombi.

M. R. Gautam

Desert Research Institute, Las Vegas, NV, USA

K. Chief $(\bowtie)$

University of Arizona, Tucson, AZ, USA

e-mail: kchief@email.arizona.edu

W. J. Smith Jr.

University of Nevada, Las Vegas, NV, USA 
the western U.S. (Barnett et al. 2005). One hotspot, where climate change impacts are potentially significant, is in the Sierra Nevadas where water rights have been contested for nearly a century (Wilds 2010). Recent studies in the Sierra Nevadas have exposed vulnerabilities to climate change in terms of hydrologic response (Dettinger et al. 2004; Maurer 2007) and hydropower (Vicuña et al. 2008). These studies integrate key northern Californian cities, but other sub-areas are not well studied, with the exception of Grantz et al. (2007) who studied Truckee and Carson River Basins for water management. The river basin of interest for our study, the Truckee River Basin (TRB) (Fig. 1) is nested within a this broader area of general research interest (Regonda et al. 2005). One common aspect of these studies is their focus on biophysical impacts and an implicit assumption that social vulnerabilities have a limited role in defining climate change impacts.

In TRB, tensions regarding water rights are high, and climate change may upset a delicate balance for Native American tribes like the Pyramid Lake Paiute Tribe (PLPT) in meeting water demands for a growing population and in maintaining healthy ecosystems. PLPT, the largest tribe in Nevada, is dependent on Pyramid Lake, which is the terminus of the Truckee River. The Truckee River begins at Lake Tahoe, with headwaters in California's Sierra Nevada Mountain Range and flows through semi-arid Reno-Spark area, metropolitan area, before terminating at Pyramid Lake. Pyramid Lake is extremely important for biodiversity, socio-cultural, and economic reasons and is home to the federally listed endangered fish cui-ui (Chasmistes cujus) and the threatened fish Lahontan cutthroat trout (LCT; Salmo clarkii henshawi).

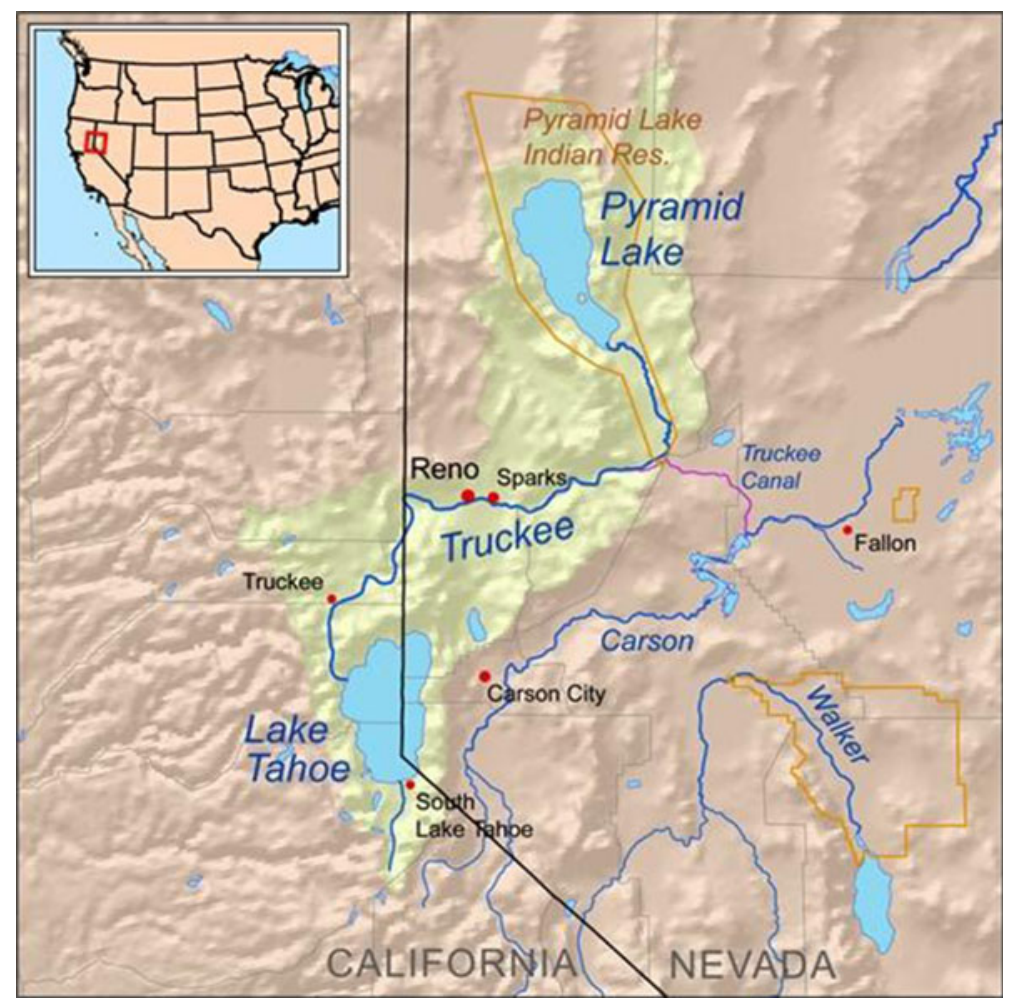

Fig. 1 Truckee River Basin Showing Pyramid Lake Indian Reservation (Credit to Karl Musser) 
PLPT's legal rights and decision-making are important for two main reasons. First, they live at the river's terminal end which exposes them to upstream users and impacts. Second, their identity and livelihood are deeply connected, culturally and economically, to Pyramid Lake and its fish. PLPT's Paiute name is Kuyuidokado, or cui-ui eaters, named after the Pyramid Lake sucker fish which was one of their main food sources before its drastic decline in the early 1900's due to Derby Dam, water use, and drought. Culturally, the Paiute origin story is based on Pyramid Lake and its tufa-rock formation, called the Stone Mother that represents a woman with a basket whose tears created the lake (Wheeler 1987). Today, fishing and recreational activities are central to PLPT economy.

Like many Native American tribes, PLPT is especially vulnerable (Smith et al. 2001) to both climatic and non-climatic stressors because of their reliance on natural resources for spiritual and socio-cultural practices (Jostad et al. 1996); dependence on local natural resources (Adger 2003; Thomas and Twyman 2005); and lower socio-economic conditions (Sarche and Spicer 2008). However, literature on climate change impacts and climate change vulnerability of Native American tribes is lacking. One notable exception is the study of climate change impacts on the Inuit in Arctic Bay, Canada (Ford and Smit 2004). Despite similarity in socio-economic status and traditional values related to symbiotic relationships with nature, considerable variations of vulnerabilities exist across the diversity of Native American tribes and Artic indigenous communities (Cochran et al. 2013; Maldonado et al. 2013). This variation is shaped by factors internal to tribal society such as traditional and cultural preferences on livelihood means and practices, as well as external socio-economic and political factors.

Besides the traditional technical approaches, understanding PLPT's vulnerability to climate change requires thoughtful consideration of values, history, and other local socioeconomic and political contexts. Byg and Salick (2009) underline the importance of local perception of climate change, impact assessment, and adaptation planning. Despite their importance, vulnerability assessments pose significant challenges due to contradictory definitions, multiple frameworks, and numerous discourses (O'Brien et al. 2007), nevertheless, there are increasing efforts to reconcile these approaches (Füssel 2007). In this study, we present an analysis of critical aspects of PLPT's social vulnerability to climate change that paves a way towards achieving an integrated analysis in the future that will merge biophysical and socioeconomic vulnerabilities and use model driven (top-down) and local perception-knowledge driven (bottom-up) approaches. The objectives of this study are to 1) identify and evaluate critical socio-economic factors contributing to the vulnerability of the Pyramid Lake Paiute Tribe to climate change impacts and 2) assess the adaptive capacity of the Pyramid Lake Paiute Tribe to climate change.

\section{Methods}

\subsection{Surveys and interviews}

Descriptive approaches were utilized in this study and qualitative data (PLPT perception and observation) were collected at household and organizational levels. Using a human ecology approach (Füssel 2007) that emphasizes human behavior and perception, a survey was conducted to assess value, belief, and perception on climate change impacts and vulnerabilities at the household level. In February 2010, questionnaires were mailed to 687 households with pre-stamped return envelopes. To increase the response rate from $5 \%$ to $16 \%$, surveys were conducted house-to-house and at a powwow held on the PLPT 
reservation during November and December 2010. In January and May 2011, household surveys were followed by semi-structured interview with key executives of various PLPT departments (environmental managers and tribal council). A purposive and snowball sampling method (Kemper et al. 2003) was applied for both surveys where selected high level decision-makers, environmental managers, and recommended subjects were recruited for interviews. Following Ford and Smit (2004), broad themes and topics were prepared as an interview guide (Table 1). We supplemented these themes through secondary data collected from household surveys and published reports.

\subsection{Vulnerability assessment framework}

One of the critical problems in vulnerability assessment (VA) is defining vulnerability. As Adger et al. (2004) note IPCC framework has two different definitions - one describing outcome, and the other the context. Thus, these, two different definitions would lead two different outcomes (O’Brien et al. 2007; Adger et al. 2004). To tackle vulnerability, we utilized the IPCC's integrative framework for vulnerability (Eq. 1), where vulnerability as an outcome is a function of three variables: exposure, sensitivity, and adaptive capacity.

Vulnerability $=\mathrm{f}($ exposure, sensitivity, and adaptive capacity $)$

Table 1 Interview checklist with key themes and topics covered (adapted from Ford et al. 2006)

\begin{tabular}{|c|c|}
\hline Key theme & Topics covered \\
\hline $\begin{array}{l}\text { Context and Community } \\
\text { Life }\end{array}$ & $\begin{array}{l}\text {-Environmental Setting (geography, geology, climate, natural resources, etc.) } \\
\text {-Family and Community Relationships (clans, kinship, family names, } \\
\text { spiritual and government leaders, etc.) } \\
\text {-Language, Culture, and Religion } \\
\text {-Life Cycle (birth-death and major life markers, feasts, celebrations, } \\
\text { and ceremonies) } \\
\text {-Major Issues and Challenges (social and cultural with links to } \\
\text { climate change) } \\
\text {-Seasonal Activities (cultural, social, and livelihood) } \\
\text {-Tribal Origin and History (migration patterns, creation stories, adaptation, } \\
\text { colonization, western settlement, Indian wars, treaty and reservation era, } \\
\text { boarding school era, civil rights, modern day, etc.) }\end{array}$ \\
\hline $\begin{array}{l}\text { Adaptive Capacity and } \\
\text { Vulnerability }\end{array}$ & $\begin{array}{l}\text { - Livelihood Assets or Capitals (financial, natural, physical, socio-cultural, } \\
\text { and human) } \\
\text { 1. Climate Change Awareness } \\
\text { 2. Education } \\
\text { 3. Local Knowledge and Practices } \\
\text { 4.Income Diversification, Agricultural Dependence, and Seasonal Migration } \\
\text { 5. Social Capital (social network, inequality, individualism, social division } \\
\text { and tension, income sharing within household, role of elders) } \\
\text {-Institutional Arrangement and Capacity for EnvironmentalIssues } \\
\text {-Institutional Support from External Agencies (e.g. federal government, NGO, } \\
\text { environmental groups etc.) } \\
\text {-Policies, Institutions and Processes (decision making, governance, resource use } \\
\text { and access) } \\
\text {-Power Relation and Access to Resources }\end{array}$ \\
\hline
\end{tabular}


Exposure refers to what is being exposed (the system that is at risk under climate change such as population, resources, or property) and the change in climate that the affected system will face (e.g. temperature, precipitation, extreme events, sea level etc.).

Adaptive capacity as defined in 4AR (IPCC 2007) is the ability of a system to successfully respond to climatic variation and change and is facilitated through adjustment in behavior, resources, and technology. Adaptive capacity is determined by socioeconomic and political factors: 1) Resources/assets; 2) Access to resource influenced by equity and sustainability; and 3) Support mechanisms (Eq. 2).

\section{Adaptive Capacity}

$=\mathrm{f}[$ resources/assets, access to resource (equity and sustainability), support mechanism]

According to Füssel (2007), social vulnerability as well as biophysical vulnerability (outcome) can be better studied through considering both internal and external factors (Eqs. 3 and 4).

$$
\begin{aligned}
\text { Internal }= & \mathrm{f}(\text { Socioeconomic: social, cultural, attitudinal; Biophysical: local geography } \\
& \text { and environmental conditions })
\end{aligned}
$$

External $=\mathrm{f}$ (Socioeconomic: national policy, power relation with regional stakeholders, external support; Biophysical: floods, droughts, temperature rise, reduced snowpack etc.)

In this study following Adger et al. (2004), we retain the term biophysical vulnerability as risk (outcome) as in disaster risk reduction literature, which is a function of hazard, exposure, and sensitivity. While stressors and perturbations characterize hazard, social vulnerability and capacities explain the exposure, and sensitivity of the systems. Following Füssel (2007), we classify socioeconomic factors as the one internal to the system and dependent on factors such as local response capacity which operate at local scale (e.g. based on chosen scale of analysis it can be household or community or state) or external (external socio-economic, political, environmental factors) operating at larger scale (e.g. national policies, external assistance, economic globalization).

\section{Context and community life}

Indigenous people have inhabited the Great Basin (a multi-state endorheic area surrounded by North America's Pacific Watershed that includes most of Nevada and Utah) for at least 4,000 years (Wagner and Lebo 1996). Northern Paiutes in the Great Basin or Numa organized into discrete bands based on their primary subsidence. According to Wheat (1977), Paiutes followed a seasonal migration pattern over Great Basin deserts in search for food. Pyramid Lake Paiutes remained close to Pyramid Lake during winter and early spring to fish for trout and hunt birds migrating along the Pacific Flyway. During May, other Paiute tribes traveled to Pyramid Lake to participate in the annual cui-ui spawning and celebration (PLPT and USDA NRCS 2005). Cui-ui fish would be gathered and dried for future uses. In the summer and fall, Pyramid Lake Paiutes traveled in search of roots, seeds, 
and berries and hunted marsh ducks close to water sources (Wheat 1977). The autumn pine nut harvest was an important cultural event for the tribe and after traveling to the best harvest site, they performed ceremonies like the pine nut prayer dance and participated in betting games with other Paiute tribes. Pine nut harvests continued through the fall, as tribal members followed pine nut ripening into the mountains. Usually in November, community rabbit drives were held in desert grasslands. After the harvests were completed, families returned from the mountains to participate in rabbit hunts (Wheat 1977).

In 1859, the Bureau of Indian Affairs (BIA) set aside a reservation for PLPT. Many tribal members adapted to the loss of their livelihood by finding work in white settlements. The settlers established ownership over ancestral Paiute lands, further limiting the customary seasonal migration. Some cultural practices, such as rabbit drives, duck hunting, and gathering of nuts, roots, seeds, and berries, were lost due to non-tribal settlement and exploitation. However, PLPT's cultural values continued to center around Pyramid Lake and tribal land, and basketry remained a symbol of native identity among many tribes. Today, modern cultural values and social networking through pow-wows, ceremonies, and rituals also represent tribal social assets.

\section{Results for socio-economic vulnerability factors}

\subsection{Internal factors}

In our analysis, internal socio-economic vulnerability factors for PLPT were well captured with livelihood assets (or capitals) and can broadly explain general adaptive capacity at the community or household level, and thus could be considered for describing vulnerability to climate change.

\subsubsection{Education and employment}

Education, economic wellbeing, and diversification of livelihoods are important indicators of adaptive capacity (Adger et al. 2004). Our survey showed that the education and economic wellbeing of PLPT members is slightly better than the overall national average for Native Americans (from the U.S. Census 2010, $34 \%$ of PLPT members surveyed attained a 2 or 4 year college degree versus $23 \%$ of Native Americans) and PLPT's degree attainment rate is close to the mainstream U.S. (38\%). Although PLPT's subsistence historically was based on fishing and collecting foods (Interview), in the current context, such subsistence is impractical due to changing tribal lifestyles and values and is replaced by economic opportunities on and off the reservation. The primary source of employment in Nixon (where $25 \%$ of tribal population resides) is tribal government or agriculture while in Sutcliffe (with $15 \%$ tribal population), employment is recreation and small commercial enterprises. The most populated community, Wadsworth (with $50 \%$ of tribal population), is close to Fernley and Reno and is PLPT's commercial hub (PLPT and USDA NRCS 2005). Interviews suggest that there are limited opportunities to diversify household/personal income due to the lack of economic growth and opportunities on the reservation.

\subsubsection{Climate change perceptions}

About $80 \%$ of the surveyed PLPT members were aware of climate change and observed changes in their environment. About $73 \%$ of respondents believe climate change is 
happening and $73 \%$ also believe that humans play a role in climate change. This contrasts to the generally low belief ( $63 \%$ ) of climate change and human role (29\%) among other rural Nevada groups and the nation (36\%; Borick and Rabe 2010). In addition, a much larger percentage of respondents $(93 \%)$ expressed their priority for climate change action at the national level compared to rural Nevada (16\%) and the nation (54\%, Leiserowitz et al. 2009). Similarly, tribal environmental managers and leaders were overwhelmingly aware of climate change issues. Climate change awareness and traditional ecological knowledge are key to successful adaptation (Wall and Marzall 2006, Hardison and Williams, this issue; Whyte 2013).

\subsubsection{Institutional capacity}

Administrative tribal resources and knowledge were reviewed to assess adaptation potential including existence of management plans such as natural resources management, disaster risk reduction planning, and prior experience with climate change adaptation/vulnerability studies. Tribal managers and leaders were knowledgeable in science-based natural resource management and collaborated with academic, research, federal, state, and other agencies to conduct research and implement projects. Several management plans were completed and tribal environmental managers were actively involved in their preparation. For example, PLPT developed the Comprehensive Resource Management Plan (CRMP; PLPT and USDA NRCS 2005), which covers planning for all forms of natural resources including wetlands and rangeland. Other available plans include Water Quality Control Plan (WQCP), water system master plan, emergency response plan, and air monitoring plan. Unique among tribes, in 2007, PLPT received Treatment As State Status pursuant to Sections 303 and 401 of the Federal Clean Water Act by the Environmental Protection Agency (EPA) for Program Authority to conduct Water Quality Standards (WQS) and 401 Certification. Since 2008, PLPT had a tribal- and EPA-approved WQCP, which was revised and reviewed extensively for 7 years. In addition, PLPT is involved in the Truckee River Flood Project and implements a conservation and management plan to protect and conserve Pyramid Lake Fisheries. Since 1974, PLPT successfully managed hatcheries and monitored water quality at Pyramid Lake, lower Truckee River, and tribal wetlands. Similarly, PLPT took a proactive approach to monitor invasive species in Pyramid Lake in the wake of Quagga Mussel invasion in Rye Patch and Lahontan Reservoirs. Finally, since 2008, PLPT has been the team lead for water management of the Stampede Reservoir with an objective to ensure long-term viability of the cui-ui, LCT, and Truckee River ecosystem. Although not all environmental divisions in PLPT showed prior experience on climate change vulnerability and related studies, it was clear that there was a strong willingness and common desire among tribal managers to include climate change in their respective programs.

\subsubsection{Technology}

While not specifically prepared for climate change impacts at present, PLPT has strong potential for climate change adaptation and integrating improved technology, however, the tribe is dependent on federal support which is extremely limited and underfunded (e.g., Indian Health Service). For example, in 2010, only $0.007 \%$ of the fund states received from U.S. Fish and Wildlife Service (FWS) was available competitively to 565 federally recognized tribes. Similarly, in 1999, BIA reported \$356 million of unmet tribal natural resource management and in 2012, tribes requested $\$ 8.75$ million for DOI Climate Change Adaptation Initiative but only $\$ 200,000$ was planned to be available. Nonetheless, PLPT has a solid 
tribal administration that is capable of implementing climate change adaptation programs with appropriate support. Existing collaborations and network with universities, research institutes, federal organizations, and other non-profit groups can help develop solutions for climate change impacts and integrate innovative technology. This network has already contributed to building tribal scientific capacity and has supported tribal administration in several environmental and resources management projects.

\subsubsection{Physical capital}

PLPT's physical capital was assessed to determine potential adaptive capacity to climate change. For PLPT, DOI is largely responsible for basic infrastructure on the reservation while several other federal agencies like EPA and U.S. Army Corps of Engineers have contributed to water quality management and flood control respectively. There were no specific infrastructure to deal with potential climate change, but several types of infrastructure meant for climate variability appear to contribute to adaption potential.

First, PLPT operates five hatcheries to maintain cui-ui and LCT populations in Pyramid Lake and the Truckee River and provide a cushion during drought years. They are: 1) Big Bend Hatchery in Wadsworth, NV to incubate and release larval cui-ui to a wetland area along the Truckee River; 2) Numana Hatchery 8 miles north of Wadsworth along the Truckee River to raise LCT from fry to fingerling size; 3) Dunn Hatchery on the west shore of Pyramid Lake in Sutcliffe, NV to incubate LCT eggs; 4) Koch Cui-ui Hatchery in Sutcliffe to raise endangered cui-ui to supplement lake population; and 5) Lake Operations Facility in Sutcliff to artificially spawn, acclimate, and stock LCT. Similarly, reservoir storage that is dedicated to 'fish' use also enhances the adaptive capacity of PLPT.

In the three PLPT tribal communities, varying water challenges exist and water infrastructure influences adaptive capacity. In Sutcliffe, arsenic contamination and lack of alternate water sources is an urgent issue (PLPT and USDA NRCS 2005). In Nixon, poor water distribution networks are a major concern. In Wadsworth, rapidly a growing population and increasing water demand is a major challenge, thus, a lack of consistent supply of drinking quality water is an issue. However, Wadsworth's de-centralized water systems is a positive aspect of water management because such systems impart flexibility and exhibit economic and environmental sense (Pahl-Wostl et al. 2007), thus contributing to better adaptive capacity to climate change.

Finally, agriculture is inadequate to support farmers' livelihood because of the lack of ownership, financial capital, and farm insurance; relatively small agricultural plots; and presence of invasive and noxious weeds. This results in seeking alternative sources of income. Climate change can impact agriculture through increased invasive and noxious weeds and increased flooding can put pressure on marginal farmers.

\subsubsection{Economic resources and financial capital}

Pyramid Lake, through recreational activities such as fishing and camping permits, contributes approximately $60 \%$ of internal tribal revenue. Ranching and agriculture were also reported to contribute income to some tribal members and are cultural practices for many. Both survey and interviews revealed that the tribe's most crucial natural asset is Pyramid Lake. The prospects of geothermal and other solar energy projects on the reservation, and more importantly, potential use of the Truckee River Operating Agreement (TROA) settlement fund for PLPT's economic development show some prospect for a diversified economy and may enhance the adaptive capacity to cope with climate change. However, energy 
opportunities are largely unexplored and uncertain and the economic development fund is tied to TROA implementation, which remains uncertain due to legal hurdles.

\subsubsection{Social capital}

While governance, institutions, and networks are generic indicators for adaption to any shocks or stresses, they are also useful indicators for climate change adaptation. PLPT has a democratic governance structure and election process. The tribal governing body (tribal council), consists of 10 members elected bi-annually, including eight tribal council members, a tribal chair, and a tribal vice-chair. The household survey revealed that $72 \%$ of surveyed tribal members participate in tribal voting. Similarly, public participation with various level of consultation appears to play a major role in key issues. For instance, in the mid 1980's, the California-Nevada Interstate Compact settlement was subjected to tribal referendum and subsequently, tribal support to the compact was withdrawn (Wilds 2010). In 2008, TROA was also set for tribal referendum before PLPT legally accepted it. Issuance of public information notices on various aspects of environmental management and administration is a common practice for PLPT. The tribal council's decision-making is based on voting; yet there is a consensus on safeguarding tribal interest and entitlement. There are several active religious and social organizations that show potential for emergency mobilization under extreme events or disasters. Interviews revealed that emergency response occurred in the aftermath of the 1997 flooding (a 117-year flood event). Another positive factor demonstrating PLPT's adaptive capacity was the presence of external networks for climate change related studies and knowledge. As mentioned, the PLPT administration (various divisions) has developed a good external network with several entities. This network appears to provide effective consultation or building capacity for climate change adaptation planning. Additionally, PLPT has maintained a strong network with other tribal nations and their consortiums which can potentially enhance its adaptive capacity. However, there were concerns that PLPT members appear to be progressively leaning towards individualism at household and community levels. Elders are socially respected, but they do not have any formal position or power unless elected to tribal council. Intergenerational segregation can put the older generation at risk and individualism can collectively lead to reduced risk sharing and adaptive capacity.

\subsubsection{Natural capital}

Key indicators contributing to adaptive capacity related to natural capital include biodiversity and conservation of natural resources. The lake and fisheries are the major natural resources on the reservation. Both groundwater and surface water also contribute to tribal water resources, and there is potential for geothermal and solar energy development. Presence of rangelands, wetlands, and agriculture (although small) shows there is some level of diversified natural resources. While conservation does not appear to be a key issue at present (given relatively small population) and priority (e.g., irrigation), tribal administration appears to understand its role. Water conservation plan with price incentives for water conservation and installation of water meters were identified in Comprehensive Resource Management Plan (CRMP), amid concerns of decreasing water supply. In addition, increasing presence of invasive species such as noxious weeds, insect pests, and bullfrogs were additional sources of concern to the tribe (PLPT and USDA NRCS 2005). Nevertheless, the awareness and ongoing initiatives in invasive species control in collaboration with other agencies shows PLPT's strong resource management potential. 


\subsection{External factors}

In our analysis, the external socio-economic vulnerability factors were linked to social, economic, legal, and environmental processes that include and extend beyond the system. As a downstream user, PLPT's vulnerability also depends on political and legal power and other stakeholders (e.g., state and federal). Similarly, as many conflicts are settled in court, judicial decisions have strong control over socioeconomic vulnerability factors.

\subsubsection{Federal support and entitlement}

As economic development on tribal lands is a relatively new concept, tribes are largely dependent on federal support. Under the federal "trust responsibility," the federal government is mandated with fiduciary duty towards federally-recognized Native American tribes. With such duty, the BIA supports several basic infrastructures such as education, health, and roads. Institutional support by several federal agencies (e.g., EPA and FWS) has been crucial to PLPT in its quest for water rights and ecological protection. Thus, tribal capacity to adapt to climate change may hinge largely on federal support and reduce their adaptive capacity. Federal support can buffer the impact of climate change on tribes, but any economic downturn under climatic or non-climatic stressors might influence the DOI budget and reduce federal support to tribes. In the past, DOI experienced budget cuts and subsequently reduced tribal programs. Such reduction on federal budget can lead to further stress on already underfunded health services (Roubideaux 2002), especially under climate change impacts (Doyle et al., submitted for this issue).

\subsubsection{Power relation and legal stressor}

Native American reservations are nested within states and thus share and compete for natural resources with other resource users. While entitlement and access to resources can greatly determine the ability to adapt, there may be legal or institutional barriers that impede tribal entitlement and access to resources. Historically, under Orr Ditch Decree Rights of 1944, PLPT's share of water rights was limited to senior irrigation water rights of 14,742 acre-feet. On the contrary, Newlands Project (agriculture in Fernley and Fallon) received the majority of the senior water rights and water was diverted from Derby Dam, largely impacting Pyramid Lake fisheries and tribal livelihood. Tribes went through relentless legal battle for water rights for fisheries and succeeded to forge a win-win relationship with Truckee Meadow Water Authority. While this success appears mostly attributed to Endangered Species Act (ESA) and listing of cui-ui as endangered species, factors including tribal leadership, exemplary relentless legal fighting, and negotiation helped them protect their water rights for Pyramid Lake. At present, PLPT owns storage for 'fish water' in Stampede Reservoir. This storage has enhanced tribal adaptive capacity to climate change impacts to Pyramid Lake fisheries and ecosystem. Upstream storage for fishery purposes will be further enhanced by TROA reservoir operating policies if and when they are approved for implementation by the courts.

TROA provides a detailed but complex framework for reservoir operation imparting flexibility on water sharing under climatic variability (Doremus and Hanemann 2008; Wilds 2010). It has several storage allocations for droughts, municipal and industrial, fish, water quality, and other purposes. The severity of regional drought impacts on Pyramid Lake fisheries depend on drought frequency and duration, lake inflow and water level, predatorprey relationship, water quality, and other environmental variables. Thus, a detailed 
understanding of potential impacts on cui-ui requires a comprehensive study using the TROA reservoir operation model coupled with a rainfall-runoff (watershed) model in both Truckee and Carson River basins.

\subsubsection{Job opportunity and migration}

Historically, tribes persevered through small climatic variations by employing adaptation strategies like diversification of food and other resources, innovative technology, rich traditional ecological knowledge, and peripheral temporary migration. They responded to bigger climatic extremes through large-scale migration, replacement of subsistence, and sociopolitical structural changes (Weiss and Bradley 2001). However, in the current context, migration is largely limited to individuals due to internal and external socio-economic pressures and a permanent tribal reservation (Cozzetto et al. 2013). Despite problems of eroding social capital, one potential positive contribution towards future climate change adaptation option at individual level is the presence of employment opportunities in urban areas. Due to limited economic opportunities, employment related migration is common among many tribal members and the survey showed $25 \%$ working off reservation. Thus, in the event of stresses from climate change and impact on current livelihood in the reservation, the existing practices of off-reservation employment can enable adaptation at the individual level.

\section{Discussion}

Our qualitative assessment of PLPT's vulnerabilities to climate change reveals several contributing elements. External socio-economic factors and processes greatly influence tribal adaptive capacity. Federal support enhances adaptive capacity at individual and reservation level and economic opportunities at Reno-Sparks does the same at the individual level. Climate change appears to bring several challenges to PLPT through impacts to the watershed, rangeland, lake, and ecosystem services. We argue that biophysical vulnerability to climate change on tribal land appears to be strongly modulated by external socioeconomic factors such as non-climatic stressors (e.g., legal, water sharing, population increase and urbanization within tribal land) which can amplify climatic impacts.

Literature suggests that effectiveness of local level processes on adaptive capacity is constrained by larger scale economic and political processes. For instance, Adger et al. (2005) argued that farmers' adaptive capacity to grow crops successfully through enabling local-scale social and physical factors is constrained by macro-scale economic processes that determine crop prices. Such importance of broader processes is quite apparent in PLPT's case. While there are quite favorable internal social and political factors for PLPT, direct and indirect dependence on external factors such as state and federal governmental policies largely constrains tribal adaptive capacity.

The interdependence between PLPT reservation and Reno-Sparks is apparent. While both the lake and reservation are linked with upstream Truckee River Basin, there is also a ruralurban network operating between the reservation and Reno-Sparks. This network has a very strong influence on the physical, social, and economic processes influencing tribal vulnerabilities and adaptive capacity. Proximity to urban centers can provide opportunities for economic development for tribes; nevertheless, they can also impact the ecological integrity of both lake and land based ecosystem on the reservation (e.g. upstream impacts on water quality and quantity) and can be modulated under climate change scenarios. Thus, upstream-downstream 
interaction should be analyzed and it should be ensured that the ecosystems are not stressed to a level limiting potential for the ecosystem to self-organize (Folke et al. 2004).

Any climate change adaption in the upstream urban region needs to be framed in a collaborative, broader watershed context, to avoid any negative externalities leading to PLPT's reduced adaptive capacity downstream. A positive factor is the increasing collaboration between Truckee Meadows Water Authority and PLPT administration in Public Law 101-618 and TROA settlements and among multiple stakeholders in various federal planning and management activities in Truckee River Watershed. In our detailed analysis of historic accords, conflicts and negotiations, we noticed that PLPT has progressively gained power through relentless legal battle, negotiation, and successful leadership and has emerged as a key player.

Studies have shown that adaptive capacity can also be created (Lemos et al. 2007) through creation, distribution, and communication of knowledge; encouragement of institutions to learn and incorporate changes; and empowering people by raising income and education. This requires investment in people and on processes such as good governance and practices that promote better institutions and address socio-economic inequalities. In PLPT's case, there are several positive attributes at the institutional level including awareness and willingness to adapt. PLPT's proactive natural resource management activities have strong potential to lead to better climate change adaptation for natural ecosystems in the reservation. Another positive factor is the presence of external knowledge, as well as support networks, local awareness of climate change and local values, and trust in the ecosystem approach to natural resources management. Nevertheless, there is an absolute need to empower people through better income and education. While it may be possible to have a strong institutional adaptive capacity for climate change adaptation, the locals may be largely constrained due to socio-economic conditions and declining social networks. While several indicators contribute to the tribal adaptive capacity positively, lower socio-economic status at household and individual level and lack of a self-sustained economy on the reservation appears to counteract other positive factors contributing to tribal adaptive capacity.

Tribes perceive their adaptive capacity as high in a broader perspective due to pride and understanding of how Native Americans have emerged through many historic difficulties and survived over thousands of years adapting to natural and socio-political changes. Their understanding of the environment and the changes on which their livelihood depend inherently give them individual survival skills and confidence that Native American tribes will adapt under climate change (IPCC 2007). This optimism can be constructive but needs to be supported with cautious and prudent planning for the future. Moreover, there are subjective questions regarding the relationships between climate change impacts, culture, and traditional values. The present day context provides several challenges for Native American tribes. While there are broader safety nets through federal programs presently supporting tribes, the inadequacy and inherent uncertainties regarding continued support are paramount. This invokes a need for bottom-up initiatives regarding socio-economic development to enhance present as well as future adaptive capacity. Factors contributing to both present and future adaptive capacity have been emphasized considering potential trade-offs between these two (Folke et al. 2004).

Besides social, there may also be physical and technological limits to adaption (Adger et al. 2009). Under climate change, there may be surprises besides gradual change, (Kane and Shogren 2000), which together with a complex web of interacting external and internal factors may hinder the ecosystems' ability to adapt. For instance, rangeland and wetlands have already been stressed by present and past droughts on the PLPT reservation. While 
under existing climatic variability, Pyramid Lake fisheries and ecosystem may adapt, the case may be different under unexpected or unexpectedly rapid climate change. Another issue is the speed of climate change - tribes have always lived in dynamic climates, but how people and ecosystems adapt is influenced by the pace of change, as well as the magnitude.

\section{Conclusion}

PLPT's vulnerability to climate change is tied to a cultural and economic dependence on Pyramid Lake, while external socio-economic factors influence adaptive capacity and amplify potential impacts. To PLPT, the sustenance of Pyramid Lake ecosystem is extremely important for economic, spiritual, and cultural reasons and this is reflected in the fact that cui-ui, the lake, and people are considered the three central components of tribal identity. As a result, PLPT has been persistent in a successful legal battle to obtain water rights and storage for fisheries which will be enhanced by TROA reservoir operating policies if and when courts approve its implementation. Climatic and non-climatic impacts threaten the endangered cui-ui fish by decreasing water quantity and quality. However, an integrated analysis that merges biophysical and socioeconomic vulnerabilities using model driven (top-down) and local perception-knowledge driven (bottom-up) is needed to precisely quantify these impacts and uncertainties. Despite limited economic opportunities and dwindling federal support, PLPT's adaptive capacity to climate change is strengthened by sustainability-based values, technical capacity for natural resource management, proactive initiatives for invasive-species control, strong external scientific networks, and a remarkable awareness of climate change. Like many tribes, PLPT would benefit from increased federal funding for tribal climate change programs, and its resilience would be enhanced by selective sustainable economic development that is sensitive to the relatively unique context of PLPT.

Acknowledgments We express our sincere gratitude to Chairman Wayne Burke, Vice-Chairman Mervin Wright Jr., Environmental Department Manager John Mosely, Former Fisheries Director Dan Mosely and Pyramid Lake Paiute Tribe and Tribal Council. Without their support the study would have never been completed. We acknowledge the support of NSF Nevada EPSCOR seed grant (\#EPS0814372). We acknowledge support of Janine Winnemucca in administering household surveys and Kiersten Miranda in conducting interviews.

Open Access This article is distributed under the terms of the Creative Commons Attribution License which permits any use, distribution, and reproduction in any medium, provided the original author(s) and the source are credited.

\section{References}

Adger WN (2003) Social aspects of adaptive capacity. In: Smith JB, Klein RJT, Huq S (eds) Climate change, adaptive capacity and development. Imperial College Press, London, pp 29-49

Adger WN, Brooks N, Bentham G, Agnew M and Eriksen S (2004) New indicators of vulnerability and adaptive capacity. Tyndall Centre Technical Report 7, Tyndall Centre for Climate Change Research Norwich, UK

Adger WN, Arnell NW, Tompkins EL (2005) Successful adaptation to climate change across scales. Glob Environ Chang 15:77-86

Adger WN, Dessai S, Goulden M, Hulme M, Lorenzoni I, Nelson DR, Naess LO, Wolf J, Wreford A (2009) Are there social limits to adaptation to climate change? Clim Chang 93:335-354

Barnett TP, Adam JC, Lettenmaier DP (2005) Potential impacts of a warming climate on water availability in snow-dominated regions. Nature 438:303-309

Borick CP, Rabe BG (2010) A reason to believe: examining the factors that determine individual views on global warming. Soc Sci Q 91:777-800 
Byg A, Salick J (2009) Local perspectives on a global phenomenon-climate change in eastern Tibetan villages. Glob Environ Chang 19:156-166

Cayan DR, Kammerdiener SA, Dettinger MD, Caprio JM, Peterson DH (2001) Changes in the onset of spring in the western United States. Bull Am Meteorol Soc 82:399-416

Coats R (2010) Climate change in the Tahoe basin: regional trends, impacts and drivers. Clim Chang 102:435-466

Cochran P, Huntington OH, Pungowiyi C, Tom S, Chapin III FS, Huntington HP, Maynard NG, Trainor SF (2013) Indigenous frameworks for observing and responding to climate change in Alaska. Clim Chang doi:10.1007/s10584-013-0735-2

Cozzetto K, Chief K, Dittmer K, Brubaker M, Gough R, Souza K, Ettawageshik F, Wotkyns S, OpitzStapleton S, Duren S, Chavan P (2013). Impacts of climate changes on the water resources of American Indians and Alaska Natives in the U.S. Clim Chang doi:10.1007/s10584-013-0737-0

Dettinger MD, Cayan DR, Meyer MK, Jeton AE (2004) Simulated hydrologic responses to climate variations and change in the Merced, Carson, and American River basins, Sierra Nevada, California, 1900-2099. Clim Chang 62:283-317

Doremus H, Hanemann M (2008) Challenges of dynamic water management in the American West. The UCLA J Environ Law Policy 26:55-75

Folke C, Carpenter S, Walker B, Scheffer M, Elmqvist T, Gunderson L, Holling CS (2004) Regime shifts, resilience, and biodiversity in ecosystem management. Annu Rev Ecol Evol Syst 557-581

Ford JD and Smit B (2004) A framework for assessing the vulnerability of communities in the Canadian Arctic to risks associated with climate change. Arctic 57:389-400

Füssel HM (2007) Vulnerability: a generally applicable conceptual framework for climate change research. Glob Environ Chang 17:155-167

Grantz K, Rajagopalan B, Zagona E, Clark M (2007) Water management applications of climate-based hydrologic forecasts: case study of the Truckee-Carson River Basin. J Water Resour Plan ManageASCE 133:339-350

IPCC (2007) Climate change 2007: the physical science basis. Contribution of Working Group I to the Fourth Assessment Report of the Intergovernmental Panel on Climate Change. Cambridge University Press, Cambridge

Jostad PM, McAvoy LH, McDonald D (1996) Native American land ethics: implications for natural resource management. Soc Nat Resour 9:565-581

Kane S, Shogren JF (2000) Linking adaptation and mitigation in climate change policy. Clim Chang 45:75102

Kemper EA, Stringfield S, Teddlie C (2003) Mixed methods sampling strategies in social science research. In: Tashakkori A, Teddle C (eds) Handbook of mixed methods in social and behavioral research. Sage Publications, Thousand Oaks, pp 273-296

Leiserowitz A, Maibach E, Roser-Renouf C (2009) Climate Change in the American Mind: American's climate change beliefs, attitudes, policy preferences, and actions. Yale University and George Mason University. New Haven, CT: Yale Project on Climate Change.

Lemos MC, Boyd E, Tompkins EL, Osbahr H, Liverman D (2007) Developing adaptation and adapting development. Ecol Soc 12:26

Maldonado JK, Shearer C, Bronen R, Peterson K, Lazrus H (2013). The impact of climate change on tribal communities in the US: Displacement, relocation, and human rights. Clim Chang doi:10.1007/s10584013-0746-Z

Maurer EP (2007) Uncertainty in hydrologic impacts of climate change in the Sierra Nevada, California, under two emissions scenarios. Clim Chang 82:309-325

O'Brien K, Eriksen S, Nygaard LP, Schjolden A (2007) Why different interpretations of vulnerability matter in climate change discourses. Clim Pol 7:73-88

Pahl-Wostl C, Sendzimir J, Jeffrey P, Aerts J, Berkamp G, Cross K (2007) Managing change toward adaptive water management through social learning. Ecol Soc 12:30

PLPT and USDA NRCS (2005) Pyramid Lake Indian Reservation Comprehensive Resources Management Plan, Washoe County, Nevada, NRCS Nevada State Office, Reno, NV.

Regonda SK, Rajagopalan B, Clark M, Pitlick J (2005) Seasonal cycle shifts in hydroclimatology over the western United States. J Climate 18:372-384

Roubideaux Y (2002) Perspectives on American Indian Health. Am J Public Health 92:1401-1403

Sarche M, Spicer P (2008) Poverty and health disparities for American Indian and Alaska Native children. Ann N Y Acad Sci 1136:126-136

Smith A, Schellnhuber HJ, Mirza MMQ (2001) Vulnerability to climate change and reasons for concern: a synthesis. In: McCarthy JJ, White KS, Canziani O, Leary N, Dokken DJ (eds) Climate change 2001: impacts: adaptation and vulnerability. Cambridge University Press, Cambridge, pp 913-967 
Thomas DSG, Twyman C (2005) Equity and justice in climate change adaptation amongst natural-resourcedependent societies. Glob Environ Chang 15:115-124

Vicuña S, Leonardson R, Hanemann MW, Dale LL, Dracup JA (2008) Climate change impacts on high elevation hydropower generation in California's Sierra Nevada: a case study in the Upper American River. Clim Chang 87:123-137

Wagner P, Lebo ME (1996) Managing the resources of Pyramid Lake, Nevada, amidst competing interests. J Soil Water Conser 51:108-117

Wall E, Marzall K (2006) Adaptive capacity for climate change in Canadian rural communities. Local Environ 11:373-397

Weiss H, Bradley RS (2001) What drives societal collapse? Science 291:609-610

Wheat MM (1977) Survival arts of the primitive Paiutes. University of Nevada Press, Reno

Wheeler SS (1987) The Desert Lake: The story of Nevada's Pyramid Lake. Caldwell, Idaho: Caxton Printers

Whyte KP (2013) Justice Forward: Tribes, Climate Adaptation and Responsibility in Indian Country. Clim Chang doi:10.1007/s10584-013-0743-2

Wilds L (2010) Water politics in northern Nevada: a century of struggle. University of Nevada Press, Reno 